\title{
Characterization of two candidate genes, NCoA3 and IRF8, potentially involved in the control of HIV-I latency Sandie Munier ${ }^{1}$, Delphine Delcroix-Genête ${ }^{1}$, Laëtitia Carthagéna ${ }^{1}$, Audrey Gumez ${ }^{1}$ and Uriel Hazan*1,2
}

Address: ${ }^{1}$ Département des Maladies Infectieuses, Institut Cochin, INSERM U567/CNRS UMR-S 8104/Université Paris 5-René Descartes, 22 rue Méchain, 75014 Paris, France and 2UFR de Biochimie, Université Paris 7-Denis Diderot, 2 Place Jussieu, 75251 Paris, France

Email: Sandie Munier - munier@cochin.inserm.fr; Delphine Delcroix-Genête - delcroix@cochin.inserm.fr; Laëtitia Carthagéna - carthagena@cochin.inserm.fr; Audrey Gumez - gumez@cochin.inserm.fr; Uriel Hazan* - hazan@cochin.inserm.fr

* Corresponding author

Published: 23 November 2005

Retrovirology 2005, 2:73 doi:10.1 186/1742-4690-2-73

This article is available from: http://www.retrovirology.com/content/2/1/73

(c) 2005 Munier et al; licensee BioMed Central Ltd.

This is an Open Access article distributed under the terms of the Creative Commons Attribution License (http://creativecommons.org/licenses/by/2.0), which permits unrestricted use, distribution, and reproduction in any medium, provided the original work is properly cited.

\begin{abstract}
Background: The persistence of latent HIV-I reservoirs is the principal barrier preventing the eradication of HIV-I infection in patients by current antiretroviral therapy. It is thus crucial to understand the molecular mechanisms involved in the establishment, maintenance and reactivation of HIV-I latency. Since chromatin remodeling has been implicated in the transcriptional reactivation of the HIV-I promoter, we assessed the role of the histone deacetylase inhibitor sodium butyrate $(\mathrm{NaB})$ on two HIV-I latently infected cell lines (UI and $\mathrm{ACH}-2)$ gene expression.
\end{abstract}

Results: Analysis of microarrays data led us to select two candidate genes: NCoA3 (Nuclear Receptor Coactivator 3), a nuclear receptor coactivator and IRF8 (Interferon Regulatory Factor 8), an interferon regulatory factor. $\mathrm{NCOA} 3$ gene expression is upregulated following $\mathrm{NaB}$ treatment of latently infected cells whereas IRF8 gene expression is strongly downregulated in the promonocytic cell line following $\mathrm{NaB}$ treatment. Their differential expressions were confirmed at the transcriptional and translational levels. Moreover, $\mathrm{NCOA} 3$ gene expression was also upregulated after treatment of $\mathrm{UI}$ and $\mathrm{ACH}-2$ cells with phorbol myristyl acetate (PMA) but not trichostatin $A$ (TSA) and after treatment with $\mathrm{NaB}$ of two others HIV-I latently infected cell lines (OMIO.I and JI.I). IRF8 gene is only expressed in UI cells and was also downregulated after treatment with PMA or TSA. Functional analyses confirmed that NCoA3 synergizes with Tat to enhance HIV-I promoter transcription and that IRF8 represses the IRFI-mediated activation through the HIV-I promoter Interferon-stimulated response element (ISRE).

Conclusion: These results led us to postulate that $\mathrm{NCoA} 3$ could be involved in the transcriptional reactivation of the HIV-I promoter from latency and that IRF8 may contribute to the maintenance of the latent state in the promonocytic cell line. Implication of these factors in the maintenance or reactivation of the viral latency may provide potential new targets to control HIV-I replication in latent viral reservoirs. 


\section{Background}

The use of highly active antiretroviral therapy (HAART) in HIV-1 infected individuals has led to a significant decrease of plasma viremia to undetectable levels and has considerably improved the survival and quality of life of infected individuals (reviewed in [1]). However, the presence of cellular reservoirs that contain latent viruses capable of producing infectious particles after cellular activation lead to a rebound of the viral load after interruption of HAART (reviewed in [2]). The persistence of these latently infected viral reservoirs, despite prolonged HAART treatments, represents a major obstacle to the eradication of HIV-1 in infected patients [3-5]. Therefore, a greater understanding of the molecular mechanisms involved in establishment, maintenance and reactivation of viral latency is essential to expect the reduction of latent HIV-1 reservoirs in infected patients.

Latent HIV-1 infection can exist in many reservoirs, such as macrophages and resting memory $\mathrm{CD}^{+} \mathrm{T}$ cells (reviewed in [6]). At the cellular level, two major forms of HIV-1 latency have been described: pre- and post-integration latency [7]. $\mathrm{CD} 4{ }^{+} \mathrm{T}$ cells in the post-integration state of latency represent the most stable reservoir for HIV-1 (half-life of 43 months) [8]. Several mechanisms have been proposed to account for the low level of transcription observed during post-integration latency (reviewed in [9]): the inaccessibility of the integrated provirus to the transcriptional machinery, the absence in resting cells of transcription factors involved in HIV-1 gene expression, the presence of transcriptional repressors, and the premature termination of HIV-1 transcription elongation due to the absence of the viral protein Tat and its associated cofactors. Moreover, the chromatin structure appears to be involved in the regulation of HIV-1 gene expression (reviewed in [10]). Indeed, a repressive nucleosome (nuc1), located immediately downstream of the HIV-1 transcription start site under latency conditions, is disrupted upon transcriptional activation of the HIV-1 promoter in response to Tat, phorbol esters and histone deacetylase (HDAC) inhibitors [11]. Transcriptional activation of the HIV-1 promoter in response to PMA involves the recruitment of SWI/SNF chromatin remodeling complex [12] and cellular proteins with histone acetyltransferase (HAT) activity [13]. Therefore, chromatin remodeling plays a significant role in the transcriptional reactivation of the HIV1 promoter from latency. Identification of host transcription factors that may regulate chromatin structure is thus critical to understand the molecular mechanisms involved in HIV-1 reactivation.

Gene expression analysis using high-density microarrays have provided a greater understanding of host-pathogen interactions (reviewed in [14]). Previous microarray studies on HIV-1 have described changes in cellular genes tran- scription in response to HIV-1 protein expression (Nef $[15,16]$, Tat $[17,18]$, gp120 [19] or Vpr [20]) or following acute infection of cell lines [21-24] or Peripheral Blood Mononuclear Cells (PBMC) [25]. DNA microarrays have also been used to characterize gene expression in latently infected resting $\mathrm{CD} 4{ }^{+} \mathrm{T}$ cells in viremic versus aviremic HIV-1 infected individuals [26]. Recently, global gene expression changes in cell lines latently infected with HIV1 and induced by PMA for completion of viral replication was described by Krishnan et al. [27].

To complete the results obtained by Krishnan et al., we used the same strategy to assess the role of the HDAC inhibitor $\mathrm{NaB}$ on HIV-1 latently infected cells gene expression. We performed microarray experiments on two HIV1 latently infected cell lines (U1 and ACH-2) treated or not with $\mathrm{NaB}$ to induce viral reactivation. Analysis of microarrays data led us to select two candidate genes encoding transcription factors: NCoA3 (reviewed in [28]), which expression is upregulated following treatment of latently infected cells with $\mathrm{NaB}$, and IRF8 (reviewed in [29]), which expression is downregulated in treated cells. Differential expression of these genes was confirmed at the transcriptional and translational levels. Moreover, NCoA3 gene expression was also upregulated after treatment of $\mathrm{U} 1$ and ACH-2 cells with PMA but not TSA and after treatment with $\mathrm{NaB}$ of two others latently infected cell lines (OM10.1 and J1.1). IRF8 gene is only expressed in U1 cells and was also downregulated after treatment with PMA or TSA. Functional analyses confirmed that NCoA3 synergizes with Tat to enhance HIV-1 promoter transcription and that IRF8 represses the IRF1-mediated activation of the HIV-1 ISRE element. Implication of IRF8 in the maintenance and $\mathrm{NCOA} 3$ in the reactivation of the viral latency may thus provide new insights into the control of HIV-1 replication in latent viral reservoirs.

\section{Results}

\section{Microarray analysis}

In order to understand the molecular mechanisms regulating HIV-1 latency, we studied the modifications of cellular transcription using microarrays in the promonocytic U1 and T CD4+ lymphocytic ACH-2 chronically HIV-1 infected cell lines after reactivation of latency. The two cell lines were treated with $10 \mathrm{mM}$ of the histone deacetylase inhibitor $\mathrm{NaB}$. Viral reactivation was monitored by coculture with $\mathrm{P} 4$ indicating cells (Figure 1A) and measuring gag viral mRNA expression (Figure 1B). Increase in both $\beta$-galactosidase activity and gag mRNA expression showed that the viral reactivation after $\mathrm{NaB}$ treatment was efficient. Total RNAs were extracted after $24 \mathrm{~h}$ and sent to the Affymetrix Microarray Facilities for subsequent hybridization on U-133A microarrays. 

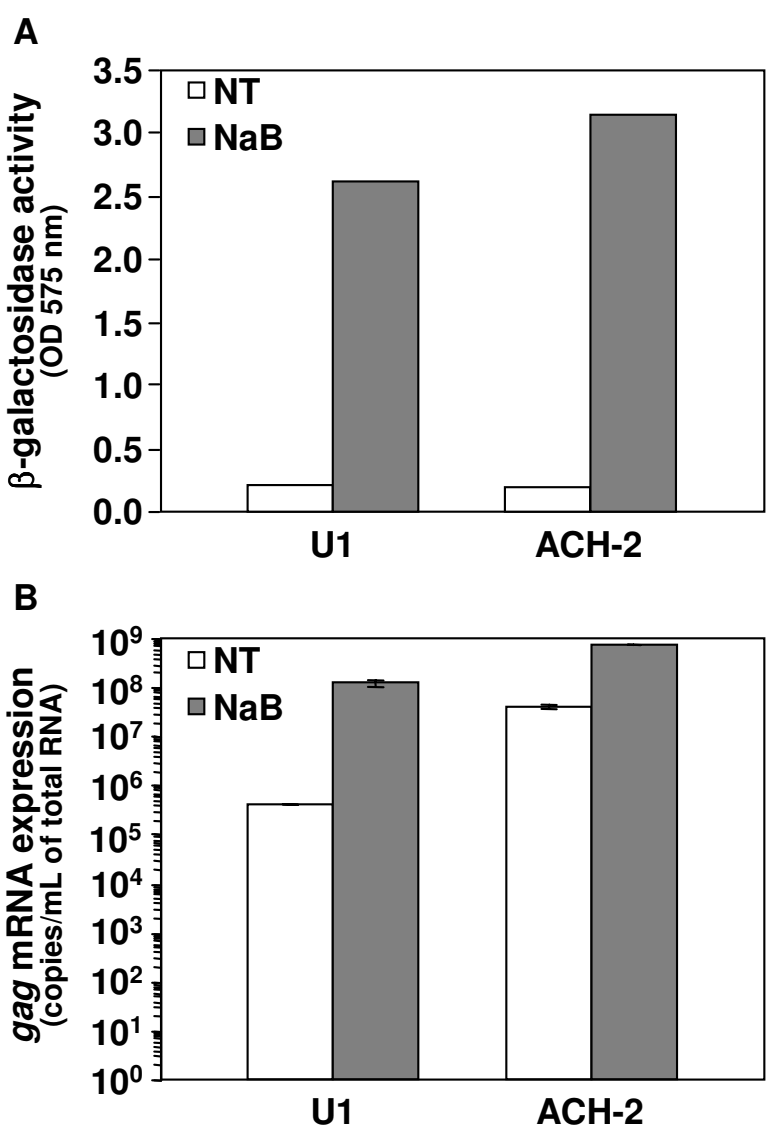

Figure I

Analysis of viral reactivation after treatment of $U$ I and $\mathrm{ACH}-2$ cells with $\mathrm{NaB}$. $\mathrm{UI}$ and $\mathrm{ACH}-2$ cells were treated or not (NT) with $10 \mathrm{mM}$ of $\mathrm{NaB}$ for $24 \mathrm{~h}$ and cocultured with P4 indicating cells. $\beta$-galactosidase activity was determined after $24 \mathrm{~h}$ coculture (A). RNA from $U I$ and $\mathrm{ACH}-2$ cells treated or not with $\mathrm{NaB}$ were extracted after $24 \mathrm{~h}$ and gag viral mRNA expression was measured by realtime RT-PCR (B). Results are representative of three independent experiments.

The pattern of cellular mRNA from chronically infected cells treated with $\mathrm{NaB}$ was compared to that from nontreated cells. We used as specific criteria a $\log _{2}$ ratio change $\geq 1$ with a change p-value $\leq 0.0001$ for increased genes and a $\log _{2}$ ratio change $\leq-1$ with a 1-change p-value $\geq$ 0.9999 for decreased genes. Hybridization experiments were performed once. We identified 740 genes that were upregulated by twofold or higher in $\mathrm{NaB}$ treated $\mathrm{U} 1$ cells and 896 genes that were downregulated, 482 genes in $\mathrm{NaB}$ treated ACH-2 cells that had a level increased greater than twofold and 634 genes that had a level decreased greater than twofold (data not shown). Moreover, 260 genes were commonly increased and 337 genes were decreased in both U1 and ACH-2 NaB-treated cells (data not shown). Pathways involved in regulation of transcription, signal transduction, immune response, protein transport, metabolism, apoptosis and RNAs modifications showed altered expression following treatment with $\mathrm{NaB}$. Some of the genes involved in these pathways are shown in Additional Files 1, 2, 3, 4, 5 and 6. Our analysis identified genes that have previously been associated with HIV-1 replication or latency, such as CDK9 [16], Jun [16,23], PSMB10 [27], MAPK1 [26] or OAS1 [30]. This supported the accuracy of our approach, even though, as the hybridization experiments had been performed once, the statistical relevance of the results could not be estimated.

Among the differentially expressed genes, we chose to focus on two candidate genes encoding transcription factors: NCoA3 and IRF8 (Tables 1 and 2). We selected these two genes based on their biological properties, their described effects on viral replication $[31,32]$ and their differential expression observed by microarray experiments. Indeed, $\mathrm{NCoA3}$ and IRF8 gene expression are respectively upregulated and downregulated following treatment with $\mathrm{NaB}$ of latently infected cells (Tables 1 and 2). Therefore, $\mathrm{NCoA} 3$ and IRF8 could be implicated respectively in the reactivation and maintenance of HIV-1 latency.

NCoA3 gene expression is upregulated following treatment with $\mathrm{NaB}$ of both $\mathrm{U} 1$ and $\mathrm{ACH}-2$ latently infected cells (Tables 1 and 2). NCoA3 is a nuclear receptor coactivator of the Steroid Receptor Coactivator (SRC) family that interacts with nuclear receptors in a ligand-dependent manner and enhances transcriptional activation via histone acetylation and recruitment of general transcription factors and additional cofactors (reviewed in [28]). NCoA3 (Unigene Hs. 382168) gene expression in U1 cells is significantly upregulated by 4.9 to 22.6 fold (U1NaBvsU1 signal $\log _{2}$ ratio ranging from 2.3 to 4.5 with a change p-value $<0.00015)$ following treatment with $\mathrm{NaB}$ (Table 1). Similarly, NCoA3 gene expression is upregulated in NaB-treated compared to non-treated ACH-2 cells by 2 to 13.9 fold but with a lower significance (ACH2NaBvsACH2 signal $\log _{2}$ ratio ranging from 1 to 3.8 with a change $\mathrm{p}$-value $<0.0055$ ) (Table 2 ).

IRF8 gene expression is downregulated following treatment of $\mathrm{U} 1$ cells with $\mathrm{NaB}$ (Table 1). IRF8 is a transcription factor of the Interferon (IFN) Regulatory Factor (IRF) family that binds to IFN-stimulated response element and regulates expression of genes stimulated by IFNs (reviewed in [29]). IRF8 (Unigene Hs. 137427) is expressed in the promonocytic cell line U1 (detection signal of 707.9 with a p-value of 0.000244 ) (Table 1) but is not expressed in the T $\mathrm{CD}_{4}^{+}$lymphocytic cell line ACH-2 (data not shown). Following NaB treatment, IRF8 gene expression in U1 cells is downregulated by 16 fold 
Table I: Differential gene expression obtained for NCoA3 and IRF8 mRNAs in UI cells treated or not with NaB.

\begin{tabular}{|c|c|c|c|c|c|c|c|}
\hline Gene & Probe set Name ${ }^{a}$ & UI Signal $b$ & $\begin{array}{l}\text { UI Detection } \mathrm{p} \text { - } \\
\text { value }{ }^{c}\end{array}$ & UINaB Signal & $\begin{array}{c}\text { UINaB Detection } \\
\text { P-value }\end{array}$ & $\begin{array}{l}\text { UINaBvsUI Signal } \\
\log _{2} \text { ratio } d\end{array}$ & $\begin{array}{c}\text { UINaBvsUI } \\
\text { Change p-value e }\end{array}$ \\
\hline \multirow[t]{5}{*}{$N C O A 3$} & 207700_s_at & 17.7 & 0.01416 & 98.9 & 0.000244 & 2.5 & 0.000035 \\
\hline & 209060_x_at & 16.9 & 0.171387 & 77.2 & 0.000244 & 2.3 & 0.000023 \\
\hline & 20906I_at & 48.4 & 0.037598 & 166.4 & 0.000732 & 2.3 & 0.00002 \\
\hline & 209062_x_at & 6.3 & 0.72583 & 91.8 & 0.010742 & 4.5 & 0.000147 \\
\hline & 211352_s_at & 7.2 & 0.303711 & 68.6 & 0.00293 & 3.2 & 0.000101 \\
\hline IRF8 & 204057_at & 707.9 & 0.000244 & 47 & 0.010742 & -4 & 0.99998 \\
\hline
\end{tabular}

${ }^{a}$ Affymetrix UI33-A reference probe set.

b Signal intensity of hybridization.

c Signal detection p-value $<0.048$ for specific hybridization.

${ }^{d}$ Signal $\log _{2}$ ratio $>$ I for increased genes and $<-$ I for decreased genes.

e Change $\mathrm{p}$-value $<0.000 \mathrm{I}$ for significant increased genes and I-change $\mathrm{p}$-value $>0.9999$ for significant decreased genes.

(U1NaBvsU1 signal $\log _{2}$ ratio of -4 with a 1 -change pvalue of 0.99998) (Table 1).

\section{Validation of NCoA3 and IRF8 differential transcriptional expression}

Real-time RT-PCR quantifications were performed to confirm that NCoA3 and IRF8 genes were differentially expressed in the NaB-treated chronically infected cells compared to the non-treated cells. We performed quantification on RNA samples obtained from five independent $\mathrm{NaB}$ treatments of $\mathrm{U} 1$ and $\mathrm{ACH}-2$ cells and real-time RTPCR experiments were run in duplicate. NCoA3 and IRF8 expressions were normalized to the expression of Cyclophilin A. The results show in Figure 2 represent the NCoA3 expression increase fold (Figure 2A) obtained from $\mathrm{U} 1$ and $\mathrm{ACH}-2$ cells and the IRF8 expression decrease fold (Figure 2B) obtained from U1 cells treated with $\mathrm{NaB}$ for $24 \mathrm{~h}$ and $48 \mathrm{~h}$ compared to non-treated cells. Concerning NCoA3, real-time RT-PCR showed an upregulation consistent with microarray data in $24 \mathrm{~h} \mathrm{NaB}$-treated U1 cells of $8.34 \pm 2.42$ fold compared to non-treated cells (Figure 2A). NCoA3 gene expression is also increased with a $48 \mathrm{~h} \mathrm{NaB}$ treatment (upregulation of $8.40 \pm 2.33$ fold) (Figure 2A). Similarly, an increase of NCoA3 gene expression can be observed on ACH-2 cells following treatment with $\mathrm{NaB}$ (upregulation of $4.56 \pm 1.28$ fold in $24 \mathrm{~h}$ and $6.80 \pm 2.34$ fold in $48 \mathrm{~h} \mathrm{NaB}$-treated $\mathrm{ACH}-2$ cells) (Figure 2A). Concerning IRF8, real-time RT-PCR showed a 14.96 \pm 4.85 fold decrease in $24 \mathrm{~h} \mathrm{NaB}$-treated U1 cells (Figure $2 \mathrm{~B}$ ) in correlation with the microarray ratio previously obtained. Downregulation of IRF8 gene expression is also observed following $48 \mathrm{~h} \mathrm{NaB}$-treatment of U1 cells (22.06 \pm 11.29 fold decrease) (Figure 2B). Taken together, results from real-time RT-PCR performed on NCoA3 and IRF8 genes corroborate with those obtained using microarray hybridizations.
We next determined whether NCOA3 and IRF8 gene expression were similarly modified in the uninfected parental cell lines. U937 and CEM cells were subjected to identical treatment and RT-PCR quantifications were performed (Figure 3). NCoA3 is upregulated both in U937 and CEM cells following treatment with $\mathrm{NaB}$ (upregulation of $7.32 \pm 1.74$ fold in $24 \mathrm{~h}$ and $11.45 \pm 2.95$ fold in $48 \mathrm{~h}$ NaB-treated U937 cells, upregulation of $1.93 \pm 1.04$ fold in $24 \mathrm{~h}$ and $5.59 \pm 0.06$ fold in $48 \mathrm{~h} \mathrm{NaB}$-treated CEM cells) (Figure 3A). IRF8 is only expressed in the promonocytic cell line U937 and, as in U1 cells, its expression was downregulated after $\mathrm{NaB}$ treatment (downregulation of $17.95 \pm 4.15$ fold in $24 \mathrm{~h}$ and $22.32 \pm 10.82$ fold in $48 \mathrm{~h}$ NaB-treated U937 cells) (Figure 3B). Thus, NaB treatment modify NCoA3 and IRF8 gene expression in uninfected parental cell lines U937 and CEM at a similar level than in chronically infected cells.

We then performed additional experiments to determine whether the gene expression variations observed could also be mediated by treatments with the phorbol ester PMA and another HDAC inhibitor, TSA. We thus assessed the differential regulation of $\mathrm{NCOA} 3$ and IRF8 gene expression in U1 and ACH-2 cells treated with PMA or TSA (Figure 4). Results indicated that NCoA3 expression is upregulated by $24 \mathrm{~h}$ and $48 \mathrm{~h}$ PMA treatment of $\mathrm{U} 1$ and ACH- 2 cells (upregulation of $5.70 \pm 1.37$ fold in $24 \mathrm{~h}$ and $9.85 \pm 0.90$ fold in 48 h PMA-treated U1 cells, upregulation of $3.12 \pm 1.05$ fold in $24 \mathrm{~h}$ and $7.12 \pm 1.20$ fold in 48 h PMA-treated ACH-2 cells (Figure 4A). However, TSA treatment had no significant effect on NCoA3 expression in $\mathrm{U} 1$ and $\mathrm{ACH}-2$ cells, although TSA increased viral expression (data not shown). Concerning IRF8 expression in U1 cells, PMA and TSA treatments for $24 \mathrm{~h}$ induced a decrease of $3.22 \pm 0.45$ fold and $5.32 \pm 1.09$ fold, respectively (Figure $4 \mathrm{~B}$ ). These results show that $\mathrm{NCoA3}$ expres- 
Table 2: Differential gene expression obtained for NCoA3 mRNA in ACH-2 cells treated or not with NaB.

\begin{tabular}{|c|c|c|c|c|c|c|c|}
\hline Gene & Probe set Name ${ }^{a}$ & $\mathrm{ACH}-2$ Signal $b$ & $\begin{array}{c}\mathrm{ACH}-2 \text { Detection } \\
\mathrm{p}^{-v a l u e}{ }^{c}\end{array}$ & $\begin{array}{c}\mathrm{ACH} 2 \mathrm{NaB} \\
\text { Signal }\end{array}$ & $\begin{array}{c}\mathrm{ACH} 2 \mathrm{NaB} \\
\text { Detection } \mathrm{p} \text {-value }\end{array}$ & $\begin{array}{l}\mathrm{ACH} 2 \mathrm{NaBv} \text { sACH } \\
2 \text { Signal } \log _{2} \text { ratio }{ }^{d}\end{array}$ & $\begin{array}{c}\mathrm{ACH} 2 \mathrm{NaBvs} \mathrm{ACH} 2 \\
\text { Change } \mathrm{p} \text {-value }{ }^{\mathrm{e}}\end{array}$ \\
\hline \multirow[t]{5}{*}{$N C o A 3$} & 207700_s_at & 43.3 & 0.001953 & 99.6 & 0.001221 & 1.2 & 0.000241 \\
\hline & 209060_x_at & 34.5 & 0.01416 & 72.9 & 0.001953 & 1 & 0.000273 \\
\hline & 20906I_at & 65.8 & 0.000732 & 82.6 & 0.000732 & 1.6 & 0.005409 \\
\hline & 209062_x_at & 20 & 0.466064 & 76.7 & 0.095215 & 2 & 0.000114 \\
\hline & 211352_s_at & 2.7 & 0.5 & 37 & 0.030273 & 3.8 & 0.004481 \\
\hline
\end{tabular}

a Affymetrix UI33-A reference probe set.

b Signal intensity of hybridization.

c Signal detection p-value $<0.048$ for specific hybridization.

${ }^{d}$ Signal $\log _{2}$ ratio $>$ I for increased genes and $<-I$ for decreased genes.

e Change $\mathrm{p}$-value $<0.000 \mathrm{I}$ for significant increased genes and I-change $\mathrm{p}$-value $>0.9999$ for significant decreased genes.

sion is upregulated following phorbol ester but not with other HDAC inhibitor treatments in U1 and ACH-2 cells. Moreover, IRF8 gene expression in U1 cells is downregulated with PMA or TSA treatments but at a lower extent than with $\mathrm{NaB}$.

We also assessed the differential regulation of $N C O A 3$ and IRF8 gene expression in others chronically HIV-1 infected cell lines. The chronically infected promonocytic OM10.1 and T CD4+ lymphocytic J1.1 cell lines were treated with $\mathrm{NaB}$ for $24 \mathrm{~h}$ and $48 \mathrm{~h}$ and real-time RT-PCR were performed to measure NCoA3 and IRF8 gene expression. As shown in Figure 5, NCoA3 expression is upregulated by $4.94 \pm 0.78$ fold in OM10.1 and by $2.56 \pm 0.64$ fold in J1. 1 after $24 \mathrm{~h} \mathrm{NaB}$ treatment. NCoA3 expression increased with time of $\mathrm{NaB}$ treatment in both cell lines (upregulation of $12.89 \pm 3.10$ fold in OM10.1 and $3.51 \pm 0.69$ fold in J1.1 cells) (Figure 5). Like ACH-2 and unlike U1 cells, the $\mathrm{T} \mathrm{CD}^{+}$lymphocytic $\mathrm{J} 1.1$ and the promonocytic OM10.1 cell lines did not express IRF8 (data not shown). Thus, the differential regulation of NCOA3 but not IRF8 gene expression is similar in two other related latently HIV-1 infected cell line models.

\section{gag mRNA activation is correlated with NCoA3 mRNA increase and IRF8 $m$ RNA decrease}

We performed reactivation experiments at different times, sooner than $24 \mathrm{~h}$ and until $48 \mathrm{~h}$. Quantitative RT-PCR experiments were carried out on total RNAs. This was done using $\mathrm{U} 1$ cells to analyze both NCoA3 mRNA increase (Figure 6A) and IRF8 mRNA decrease (Figure 6B) relative to HIV gag mRNA along with ACH-2 cells (Figure 6C) to analyze NCoA3 mRNA increase relative to HIV gag mRNA.

As observed on Figure 6C, the obtained results, both on ACH-2 and U1 cells, clearly show that gag mRNA activation occurs after NCoA3 mRNA increase and accumulation. Moreover, in U1 cells, gag mRNA activation occurs after IRF8 mRNA decrease. Shorter kinetics ( 0 to $8 \mathrm{~h}$ ) correlated with these results (data not shown).

\section{Validation of NCOA3 and IRF8 differential translational expression}

To confirm that the changes seen at the RNA level correlated with protein levels, we performed Western blot experiments on nuclear extract of U1, ACH-2, OM10.1 and $\mathrm{J} 1.1$ cells treated or not with $\mathrm{NaB}$ for $24 \mathrm{~h}$ (Figure 7). Results indicated that $\mathrm{NaB}$ increased the expression level of NCoA3 protein in U1, ACH-2, OM10.1 and not in J1.1 cells (Figure 7). Moreover, IRF8 protein expression is strongly downregulated in $\mathrm{U} 1$ cells following $\mathrm{NaB}$ treatment (Figure 7). These results correlate with the differential expression of NCoA3 and IRF8 genes observed with both microarray and real-time RT-PCR experiments.

\section{Transcriptional activation of the HIV-I promoter by NCoA3}

We analyzed the functional role of NCoA3 on viral transcription by transfection assays. HEK293 cells were cotransfected with pLTRX-luc reporter plasmid containing the luciferase gene under the control of the HIV-1 U3-R promoter region (nt -640 to +78 ) with or without Tat and/ or NCoA3 expression vectors. As shown in Figure 8, NCoA3 increased Tat-stimulated HIV-1 LTR activity by 2.8 \pm 1.4 fold. The presence of NCoA3 had synergistic effect on the HIV-1 LTR activity induced by suboptimal expression of Tat. When HEK293 cells were transfected with pLTRATAR-luc reporter plasmid lacking the Tat-transactivation response element TAR, Tat was not able to activate the LTR transcription, as expected, and NCoA3 had no effect on the LTR activity (Figure 8). Thus, functional analyses confirm that NCoA3 synergizes with Tat to enhance HIV-1 promoter transcription, as expected [31], and that this effect is dependent on the presence of the TAR region. 
A

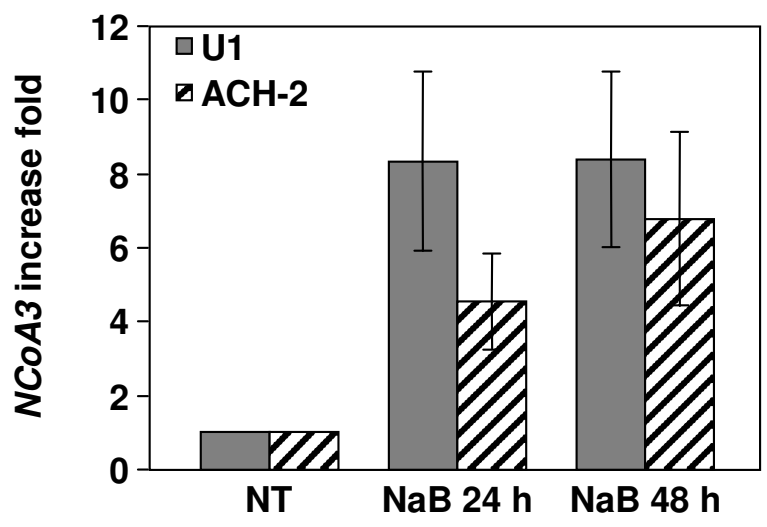

B

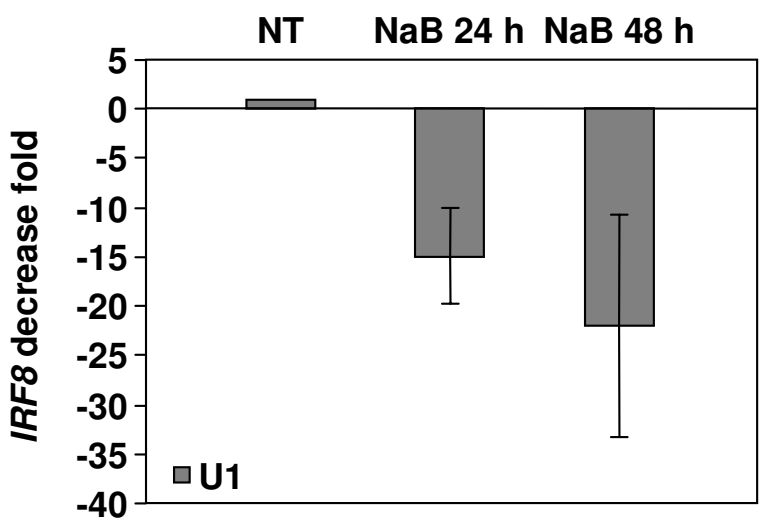

Figure 2

Real-time RT-PCR analysis of NCoA3 and IRF8 mRNAs expression in NaB-treated $\mathrm{UI}$ and $\mathrm{ACH}-2$ cells. Total RNAs were isolated from $\mathrm{UI}$ or $\mathrm{ACH}-2$ cells treated or not with $\mathrm{NaB}$ for $24 \mathrm{~h}$ and $48 \mathrm{~h}$ and real-time PCR were performed on CDNAs using gene specific primers for NCoA3, IRF8 or Cyclophilin A. NCoA3 and IRF8 expressions were normalized to the expression of Cyclophilin A. The $\mathrm{NCoA} 3$ increase fold $(\mathrm{A})$ in $\mathrm{UI}$ (solid bars) or $\mathrm{ACH}-2$ (white bars) cells and the IRF8 decrease fold (B) in UI cells treated with $\mathrm{NaB}$ for $24 \mathrm{~h}$ and $48 \mathrm{~h}$ compared to non-treated (NT) cells were determined. Results represent the means of five independent experiments performed in duplicate.

\section{Transcriptional repression of the HIV-I ISRE element by IRF8}

We analyzed the functional role of IRF8 on viral transcription by transfection assays. HEK293 cells were cotransfected with pISRE-TK-luc reporter plasmid corresponding to the HIV-1 IFN-stimulated response element, located downstream transcription start site (nt +194 to +223 ) [33], with or without IRF1 and/or IRF8 expression vectors. As shown in Figure 9, the basal activity of the ISRE-TK was increased by $7.4 \pm 1.0$ fold in the presence of IRF1 as expected [32], whereas a decrease was detected in the pres-
A

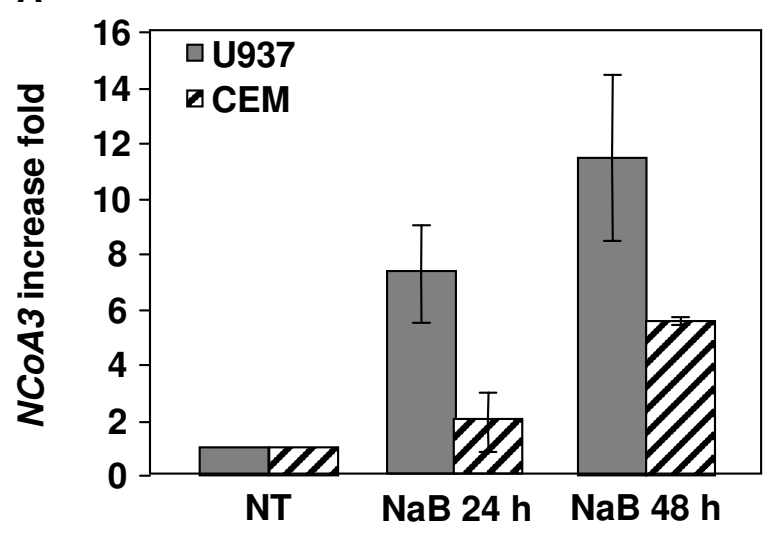

B

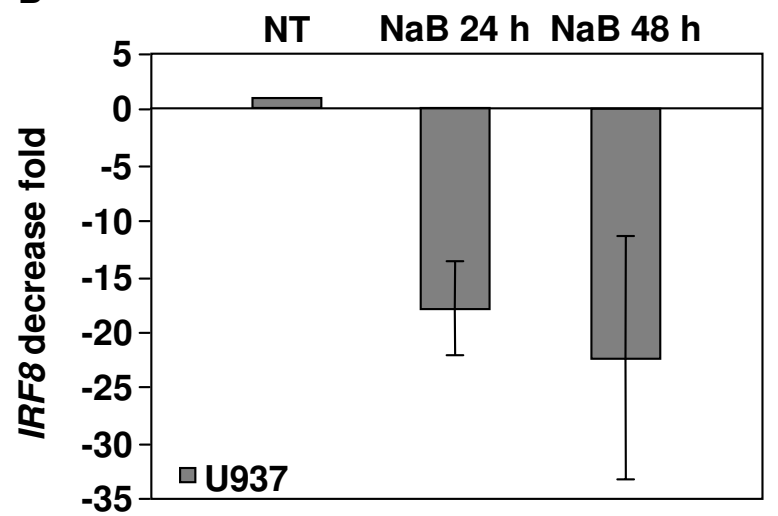

Figure 3

Real-time RT-PCR analysis of NCoA3 and IRF8 mRNAs expression in NaB-treated U937 and CEM cells. Total RNAs were isolated from U937 or CEM cells treated or not with $\mathrm{NaB}$ for $24 \mathrm{~h}$ and $48 \mathrm{~h}$ and real-time PCR were performed on CDNAs using gene specific primers for NCoA3, IRF8 or Cyclophilin A. NCoA3 and IRF8 expressions were normalized to the expression of Cyclophilin $A$. The $N C o A 3$ increase fold (A) in U937 (solid bars) or CEM (white bars) cells and the IRF8 decrease fold (B) in U937 cells treated with $\mathrm{NaB}$ for $24 \mathrm{~h}$ and $48 \mathrm{~h}$ compared to non-treated (NT) cells were determined. Results represent the means of five independent experiments performed in duplicate.

ence of IRF8 ( $21.9 \pm 10.6$ to $41.4 \pm 9.5 \%)$. The expression of IRF8 inhibited by $43.5 \pm 10.6$ to $74.7 \pm 2.5 \%$ the IRF1mediated activation of the ISRE-TK in a dose dependent fashion (Figure 9). The expression of the dominant negative IRF8 DNA-binding domain (IRF8-DBD) inhibited by $76.4 \pm 6.5 \%$ the IRF1-mediated activation of the ISRE-TK, as expected [34] (Figure 9). The inhibitory effects of IRF8 and IRF8-DBD expression and activation effect of IRF1 expression was abolished when the ISRE sequence was mutated (pISREmut-TK-luc, Figure 9). These results show that IRF8 represses the ISRE-TK promoter transcription 


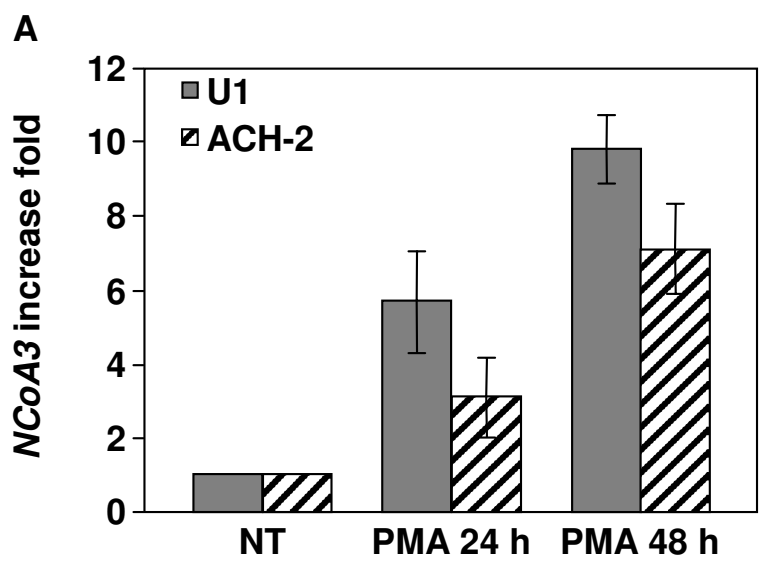

B

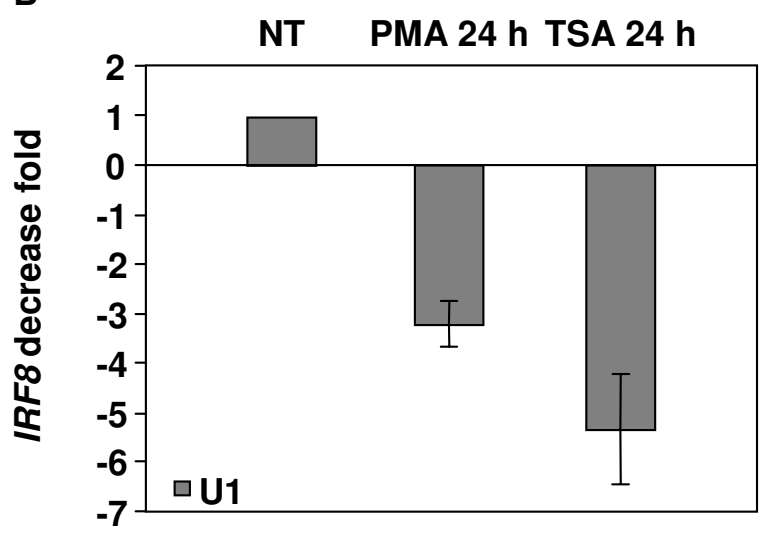

Figure 4

Real-time RT-PCR analysis of NCoA3 and IRF8 mRNAs expression in PMA- or TSA-treated $U I$ and ACH-2 cells. Total RNAs were isolated from $\mathrm{UI}$ or $\mathrm{ACH}-2$ cells treated or not with PMA for $24 \mathrm{~h}$ and $48 \mathrm{~h}$ or TSA for $24 \mathrm{~h}$ and real-time PCR were performed on CDNAs using gene specific primers for NCoA3, IRF8 or Cyclophilin A. NCoA3 and IRF8 expressions were normalized to the expression of Cyclophilin A. The NCoA3 increase fold (A) in UI (solid bars) or ACH-2 (white bars) cells treated with PMA for $24 \mathrm{~h}$ and $48 \mathrm{~h}$ and the IRF8 decrease fold (B) in UI cells treated with PMA or TSA for $24 \mathrm{~h}$ compared to non-treated (NT) cells were determined. Results represent the means of three independent experiments performed in duplicate.

through the ISRE element from the HIV-1 promoter, as expected [32].

\section{Discussion}

The existence of long-lasting HIV-1 reservoirs is the principal barrier preventing the eradication of HIV-1 infection in patients by current antiretroviral therapy. It is thus crucial to understand the molecular mechanisms involved in establishment, maintenance and reactivation of HIV-1 latency. In this study, the role of the HDAC inhibitor $\mathrm{NaB}$

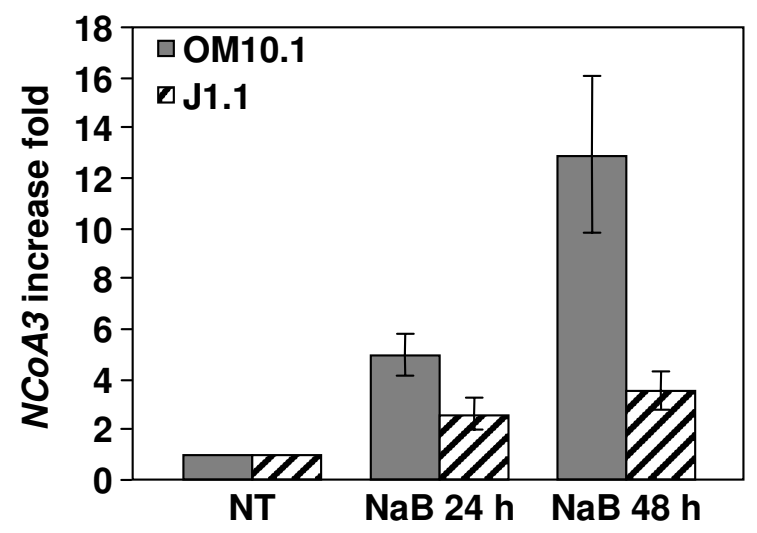

Figure 5

Real-time RT-PCR analysis of NCoA3 mRNAs expression in OMIO.I and JI.I cells. Total RNAs were isolated from OMI0.I or JI.I cells treated or not with $\mathrm{NaB}$ for $24 \mathrm{~h}$ and $48 \mathrm{~h}$ and real-time PCR were performed on cDNAs using gene specific primers for $\mathrm{NCOA3}$ or Cyclophilin A. NCoA3 expression was normalized to the expression of Cyclophilin A. The NCOA3 increase fold in OMIO.I (solid bars) or JI.I cells (white bars) treated with $\mathrm{NaB}$ for $24 \mathrm{~h}$ and $48 \mathrm{~h}$ compared to non-treated (NT) cells were determined. Results represent the means of two independent experiments performed in duplicate.

on HIV-1 latently infected cells gene expression was explored using microarrays. Since chromatin remodeling is involved in the regulation of HIV-1 gene expression (reviewed in [10]), differential expression of cellular genes in latently infected cells following treatment with $\mathrm{NaB}$ might be related to the maintenance and reactivation of latency.

Recently, Krishnan et al. [27] described the global gene expression changes in HIV-1 latently infected cell lines treated or not with PMA to induce viral reactivation compared to the uninfected parental cell lines treated under the same conditions. Here, we compared gene expression profiles of two HIV-1 latently infected cell lines (U1 and ACH-2) treated with $\mathrm{NaB}$ to that of non-treated corresponding cell lines. We thus avoided identification of genes which differential expression could result from the establishment and cloning of the chronically infected cell lines. Based on our specific criteria, we identified few hundreds of genes affected by $\mathrm{NaB}$ treatment implicated in biological pathways previously shown to be modulated by HIV-1 replication. For example, reactivation of latency induced an upregulation of CDK9, the catalytic component of transcription elongation factor $b$ (P-TEFb), which acts in concert with Tat to direct the processivity of HIV-1 transcription. It was shown that CDK9 mRNA and protein levels are induced following $\mathrm{T}$ cell activation and Nef 
A
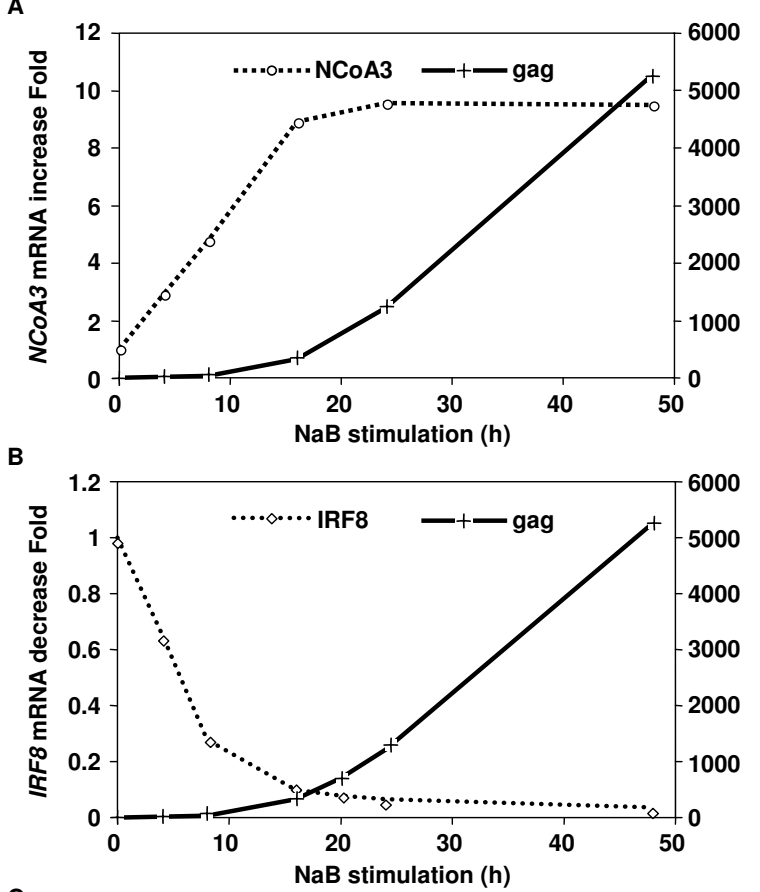

C

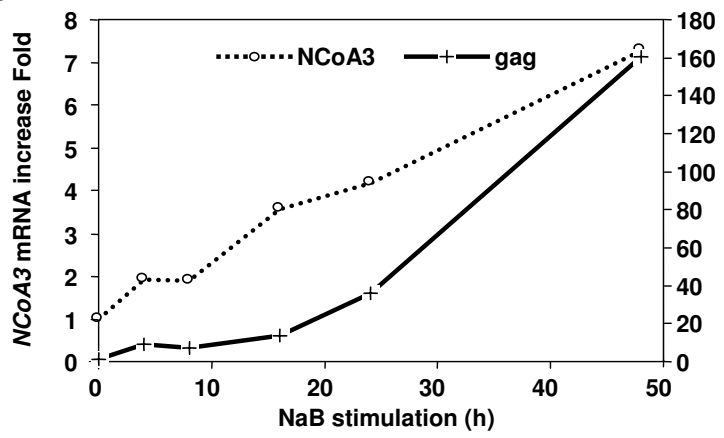

Figure 6

Analysis of HIV gag, NCoA3, and IRF8 mRNA expression after $\mathrm{NaB}$ stimulation on $U \mathrm{I}$ and $A C H-2$ cells. $U I$ $(A$ and $B)$ and $A C H-2(C)$ cells were stimulated with $10 \mathrm{mM}$ $\mathrm{NaB}$ and $5.10^{6}$ cells were taken at $\mathrm{t}=0,4,8,16,24,48 \mathrm{~h}$ for RNA extraction to perform qRT-PCR. NCoA3 (A and $C$ ), IRF8 (B) and gag (A, B and C) mRNA contents were measured. Cylophilin $A$ was used as internal standard. Results represent a representative experiment performed in duplicate.

expression, and that this correlates with kinase activity, thus enhancing HIV-1 transcription [16,35].

After $\mathrm{NaB}$ treatment of latently infected cell lines, we observed an upregulation of genes involved in vesicular transport of protein like syntaxin and nexin. It was found by Chun et al. that numerous genes involved in protein/ vesicle transport are upregulated in resting T CD4+ cells of viremic patients, strongly suggesting that enhanced activities in secretory pathways may help in the assembly and release of viral particles [26]. Recently, it was shown that multiple genes involved in cholesterol synthesis are induced by Nef [36]. NaB treatment also induced some of these genes (INSIG1, HMGCS1, IDI1, LSS or SREBF1) and could thus enhanced virion infectivity and viral replication.

Krishnan et al. have described an increase in expression of several proteasome subunits in ACH-2 cells prior induction of lytic replication by PMA and proposed that the higher expression of proteasomes may lead to increased degradation of HIV-1 mRNA [27]. After induction of lytic replication by $\mathrm{NaB}$, proteasome subunits PSMB10 and PSMB8 were downregulated in ACH-2 and U1 cells, suggesting a role in the maintenance of the latent state. Indeed, reactivation of latency was achieved with proteasome inhibitors [27]. Among the downregulated genes after $\mathrm{NaB}$ treatment, we identified genes involved in RNA modifications. Krishnan et al. have shown alterations in the expression of DEAD-box and other RNA binding proteins during HIV-1 replication [37]. Especially, DDX18 and DDX39 are upregulated in latently infected cells [37]. After $\mathrm{NaB}$ treatment of latently infected cells, we observed a decrease in the expression of these two proteins, thus providing more support for their role in maintaining HIV1 latency.

The only purpose of our microarray analysis was to identify candidate genes potentially involved in the control of the HIV latency. For this reason, we decided to focus on two candidate genes previously described to influence viral expression and that may be involved in reactivation and maintenance of latency: NCoA3 and IRF8, respectively. Hybridization experiments were performed once. Consequently, we did not further analyze the statistical relevance of the results and performed complementary approaches to confirm the mRNA variations of the selected candidate genes.

NCoA3 is a nuclear receptor coactivator that enhances ligand-induced transcriptional activation of nuclear receptors (reviewed in [28]). We show that NCoA3 (Unigene Hs. 382168) gene expression is upregulated following treatment with $\mathrm{NaB}$ of $\mathrm{U} 1$ and $\mathrm{ACH}-2$ latently infected cells. This differential transcriptional expression was confirmed by real-time RT-PCR and is also mediated by PMA but not TSA. Upregulation of NCOA3 is thus achieved following phorbol ester but not other HDAC inhibitor treatment. However, $\mathrm{NaB}$ and TSA act on different pathways and at different concentrations and target different genes [38]. Transcriptional increase of NCoA3 was observed in parental uninfected corresponding cell lines U937 and CEM and in two others latently HIV-1 infected cell lines, OM10.1 and J1.1. NCoA3 protein level is also upregulated following treatment with $\mathrm{NaB}$ in the $\mathrm{U1}, \mathrm{ACH}-2$ and 


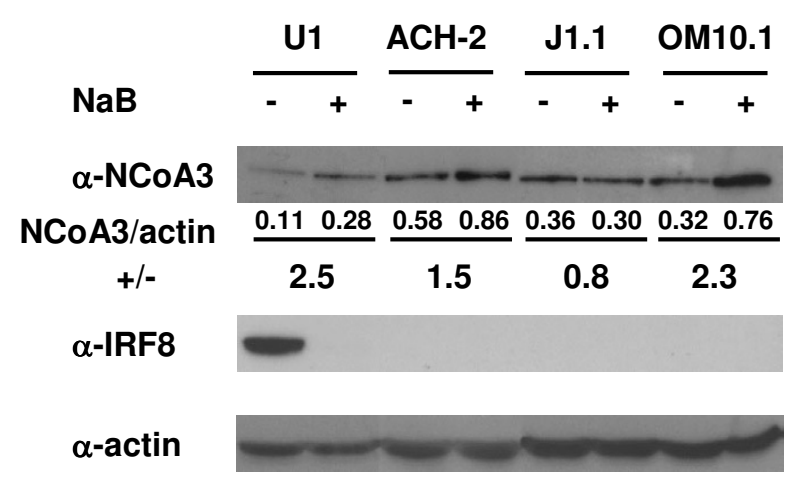

Figure 7

Western blot analysis of NCoA3 and IRF8 proteins expression. Nuclear extract (I00 $\mu \mathrm{g})$ from UI, ACH-2, JI. I and OMI0.I treated (+) or not (-) with $\mathrm{NaB}$ for $24 \mathrm{~h}$ were resolved by SDS-PAGE and immunoblotted with antiNCoA3 or anti-IRF8 antibody, as indicated. The amount of protein was normalized using anti-actin antibody. Figures below NCoA3 immunoblot indicated the results of the quantification using Image Tool (Syngene) software of the ratio $\mathrm{NCoA} 3 /$ actin upon $\mathrm{NaB}$-treatment $(+)$ versus $\mathrm{NCoA3/actin}$ non-treated (-). Results are representative of three independent experiments.

OM10.1 cell lines. Moreover, NCoA3 increases the Tatinduced HIV-1 LTR promoter transcriptional activity through the TAR region, in accordance with other data [31]. The differential expression of NCoA3 observed led us to postulate that NCoA3 could be involved in the transcriptional reactivation of the HIV-1 promoter from latency, at low concentrations of Tat.

This hypothesis is supported by several findings. Previous microarray studies on latently infected resting CD4+ T cells in infected individuals have shown an upregulation of $\mathrm{NCoA} 3$ gene expression in viremic versus aviremic patients [26]. Moreover, Kino et al. showed that NCoA factors improve Tat transactivation of HIV-1 LTR promoter activity and interact with Tat [31]. Tat transactivation activity is mediated by its interaction with components of the basal transcription machinery (including TBP, TAFII250, RNA polymerase II), with kinase complexes able to phosphorylate the C-terminal domain of RNA polymerase II (in particular with the P-TEFb complex composed of cyclin T1/CDK9) and with cellular proteins possessing HAT activity (p300/CBP, P/CAF and GCN5) (reviewed in [39]). Kino et al. showed that one member of the family, NCoA2, functions as a Tat coactivator on the HIV-1 LTR by bridging promoter-bound proteins with the Tat-P-TEFb complex through its interaction with Tat and Cyclin T1 [31]. Stimulation of Tat transactivation activity by NCoA3 could involve similar mechanisms.
Furthemore, it has been recently demonstrated that recruitment of HATs to the LTR is an early event in HIV-1 transcriptional activation [13] and that a consequence of histone acetylation is the recruitment of the ATP-dependent chromatin remodeling complex hSWI/SNF to the LTR [12]. NCoA3 could mediate chromatin remodeling by recruitment of additional cofactors with HAT activity (such as p300/CBP and P/CAF) and by an intrinsic HAT activity [40] and may thus contribute to the transcriptional reactivation of the HIV-1 promoter from latency.

IRF8 is a transcription factor that binds to ISRE and regulates expression of genes stimulated by IFNs (reviewed in [29]). IRF8 is able to both activate and repress gene transcription depending on the target gene. We show that IRF8 (Unigene Hs. 137427) gene is only expressed in the promonocytic cell line $\mathrm{U} 1$ and its expression is strongly downregulated following $\mathrm{NaB}$ treatment of these cells. This differential transcriptional expression was confirmed by real-time RT-PCR and is also observed, albeit at lower extent, after PMA and TSA treatments of U1 cells. IRF8 protein level is similarly downregulated following treatment with $\mathrm{NaB}$. Moreover, IRF8 represses the IRF1-mediated activation of the HIV-1 ISRE element of the LTR, in accordance with other data [32]. The decreased expression of IRF8 following reactivation of latency using different molecules suggest that IRF8 may contribute in the maintenance of the latent state in the promonocytic cell line.

It has been shown that binding of specific transcription factors downstream of the HIV-1 transcription start site is crucial to control HIV-1 transcription [33,41]. Among these sites is an ISRE element that recruits IRF1 and IRF2 in vivo [33]. Previous studies have investigated the role of IRFs on the modulation of HIV-1 replication (reviewed in $[42,43])$ and showed that IRF1 activates HIV-1 LTR transcription, interacts with Tat [32] and increases HIV-1 replication [44]. However, IRF8 represses IRF1-Tat-mediated transactivation of the LTR by interfering with IRF1-Tat association [32]. Moreover, it has been shown that IRF8 inhibits HIV-1 replication in T CD4+ lymphocytic and promonocytic cell lines [32,34]. These data support the hypothesis that repression of HIV-1 transcription by IRF8 could be implicated in the maintenance of proviral quiescence in latently infected cells.

Moreover, the result obtained after measurement of gag, NCoA3 and IRF8 mRNA after different times of NaB stimulation clearly showed a correlation between gag mRNA increase and NCoA3 mRNA increase or IRF8 mRNA decrease, respectively. These correlations support the hypothesis that IRF8 and NCoA3 factors may be involved in the control of the HIV latency. 


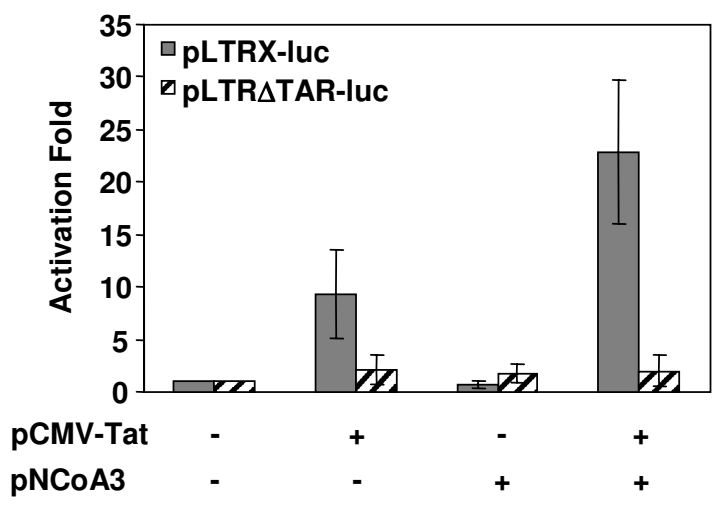

\section{Figure 8}

NCoA3 increases the Tat-stimulated HIV-I LTR activity. HEK 293 cells were cotransfected with pLTRX-luc ( $10 \mathrm{ng}$, grey bars) or pLTR $\Delta$ TAR-luc (10 ng, white bars) with $(+)$ or without (-) suboptimal amounts of PCMV-Tat (5 ng) and/or pNCoA3 $(\mathrm{I} \mu \mathrm{g})$ expression vectors. NLI (normalized luciferase index) were measured after $24 \mathrm{~h}$ and the activation folds compared to the basal activity of the corresponding pLTR-luc were determined. Results represent the means of five independent experiments.

Chronically HIV-1 infected cell lines used in this study provide useful models for studying HIV-1 latency but are not in a quiescent state as cellular reservoirs in vivo. Moreover, it has been shown that mutations in the tat gene and in the TAR sequence are responsible for the latency observed in $\mathrm{U} 1$ and ACH-2 cells, respectively $[45,46]$. We thus confirmed the differential expression of $\mathrm{NCOA} 3$ but not IRF8 genes in two others chronically HIV-1 infected cell lines, OM10.1 and J1.1. We will now investigate the involvement of NCOA3 and IRF8 to regulate viral expression in primary cells such as resting $\mathrm{T} C D 4^{+}$lymphocytes or macrophages.

\section{Conclusion}

Additional experiments are currently underway to validate the biological relevance of the differential expression of IRF8 and NCoA3 genes in latency maintenance and reactivation. Since the persistence of integrated HIV-1 genomes despite potent suppression of viral replication is a major obstacle for current antiretroviral therapy, selective disruption of the HIV-1 proviral latency may provide good strategies to decrease latent HIV-1 reservoirs. Thus, identification of cellular genes that are differentially expressed during HIV-1 reactivation of latency is crucial to understand the molecular mechanisms involved in the control of HIV-1 latency.

\section{Methods \\ Cell cultures and treatments}

The chronically HIV-1 infected T CD4+ lymphocytic cell lines ACH-2 [47] and J1.1 [48] derived from CEM and Jurkat cells respectively, and the chronically HIV-1 infected promonocytic cell lines U1 [49] and OM10.1 [50] derived from U937 and HL-60 cells respectively, were obtained through the National Institutes of Health (NIH) AIDS Research and Reference Reagent Program. Suspension cell lines were grown in RPMI 1640 (Invitrogen) with 10\% fetal bovine serum (Invitrogen), $50 \mathrm{U} / \mathrm{mL}$ penicillin, 50 $\mu \mathrm{g} / \mathrm{mL}$ streptomycin (Invitrogen) and $2 \mathrm{mM}$ glutamine (Invitrogen). Cells were treated with $10 \mathrm{mM}$ of sodium butyrate (NaB; Sigma), or with $10 \mathrm{ng} / \mathrm{mL}$ of PMA (Sigma), or with $300 \mathrm{nM}$ of TSA (Sigma). Cells were harvested generally $24 \mathrm{~h}$ and $48 \mathrm{~h}$ after treatment and cell viability was estimated before subsequent RNA extraction or nuclear extract preparation. P4 indicator cells are HeLa CD4 ${ }^{+}$cells carrying the lacZ gene under the control of the HIV-1 LTR. P4 and HEK293 cells were grown in DMEM (Invitrogen) containing $5 \%$ fetal bovine serum (Invitrogen), $50 \mathrm{U} / \mathrm{mL}$ penicillin, $50 \mu \mathrm{g} / \mathrm{mL}$ streptomycin (Invitrogen) and $2 \mathrm{mM}$ glutamine (Invitrogen).

\section{Plasmids}

The pLTRX-luc construct contains the luciferase (luc) gene downstream of the HIV-1 BRU U3-R promoter region (nt -640 to +78 ) [51]. The pLTR $\triangle T A R-l u c$ construct corresponds to the pLTRX-luc plasmid in which the TAR region (nt +38 to +78 ) was deleted [51]. The pCMV-Tat expression vector was kindly provided by $\mathrm{S}$. Emiliani (Institut Cochin, Paris, France). The pIRF8 expression vector (pcDNAmycHis-ICSBP) and dominant negative construct pIRF8-DBD, which contains the DNA binding domain of IRF8, were a kind gift of B.Z. Levi (Technion-Israel Institute of Technology, Haifa, Israel). The pNCoA3 expression vector (pcDNA3.1-AIB1) was a kind gift of P.S. Meltzer (NIH, Bethesda, USA) [52]. The pIRF1 construct was generated by cloning the fragment excised from pHuIRF-3-1 (a kind gift of T. Taniguchi, University of Tokyo, Tokyo, Japan) by HindIII/NotI digestion in the pcDNA3.1 plasmid (Invitrogen). The pISRE-TK-luc and pISREmut-TK-luc constructs were generated by cloning a wild-type (AGGGACTTGAAAGCGAAAGGGAAACCAGAG) or mutated (AGGGACTTGCCCGCGCCCGGGAAACCAGAG) synthetic oligonucleotide corresponding to the HIV-1 BRU ISRE sequence (nt +194 to +223 ) $[33,53]$ in the pTK-luc plasmid in which the luciferase gene is under the control of the truncated HSV-1 thymidine kinase promoter minimum region [51]. The pCMV-LacZ was kindly provided by M. Alizon (Institut Cochin, Paris, France).

\section{Total RNA extraction}

Total RNAs were extracted using the RNeasy Mini Kit (Qiagen). The procedure included an "on-column" 


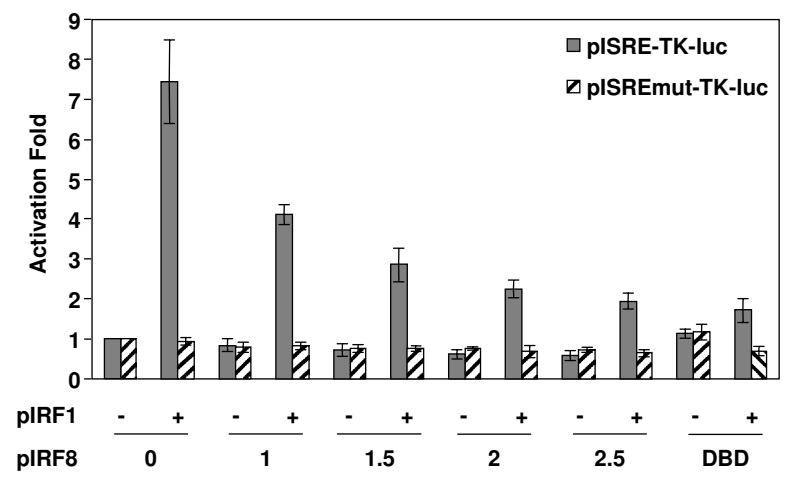

Figure 9

IRF8 represses the IRFI-mediated activation of the HIV-I ISRE element. HEK293 cells were cotransfected with pISRE-TK-luc ( $250 \mathrm{ng}$, solid bars) or pISREmut-TK-luc (250 ng, white bars) with (+) or without (-) pIRFI (250 ng), pIRF8 $(\mathrm{I}-2.5 \mu \mathrm{g})$, or pIRF8-DBD (I $\mu \mathrm{g})$ expression vectors. $\mathrm{NLI}$ (normalized luciferase index) were measured after $24 \mathrm{~h}$ and the activation folds compared to the basal activity of the pISRE-TK-luc or pISREmut-TK-luc were determined. Results represent the means of five independent experiments.

DNase I digestion step according to the manufacturer's instructions. RNA quality was assessed using the Agilent Bioanalyzer 2100 and spectrophotometric analysis prior to cDNA synthesis.

\section{Microarray experiments}

Microarray experiments were performed using the U133A microarrays (Affymetrix) containing 22283 oligonucleotides spots. Total RNAs obtained from chronically infected $\mathrm{U} 1$ and $\mathrm{ACH}-2$ stimulated or not with $\mathrm{NaB}$ for 24 $\mathrm{h}$ were sent to Dr. C. Thibault (Affymetrix Microarray Facilities, IGBMC, Strasbourg, France) for amplification, labeling and hybridization. Hybridization experiments were performed once. Results were then analyzed with the Mas5.0 Software (Affymetrix) and interpreted using the Data Mining Tool (Affymetrix) and Microsoft Excel softwares. For individual analyses, the p-value cut off was 0.048 as suggested by Affymetrix. For comparative analyses, a $\log _{2}$ ratio change $\geq 1$ for increased genes and $\leq-1$ for decreased genes were defined. Gene expression changes were considered to be significant when the change $p$-value was $\leq 0.0001$ for increased genes and 1-change p-value $\geq$ 0.9999 for decreased genes.

\section{Real-time RT-PCR}

Quantifications of cellular RNAs were performed using a Light Cycler instrument (Roche Diagnostics). Briefly, cDNAs were synthesized from $1 \mu \mathrm{g}$ of total RNA with MoMLV reverse transcriptase (Superscript II, Invitrogen) and $1 / 10^{\text {th }}$ aliquots of the corresponding samples were used for real-time PCR in a $20 \mu \mathrm{L}$ reaction mixture containing 1X LightCycler FastStart DNA Master SYBR Green I (Roche Diagnostics), $4 \mathrm{mM} \mathrm{MgCl}$, and $500 \mathrm{nM}$ of each primer. The reactions were carried out in duplicate and the results were normalized to the expression of Cyclophilin A. Primers for quantitative PCR were designed using Oligo 6 software. All primer pairs produced single amplification product as determined by melting curve analyses. The sequences of the primers used were ( $5^{\prime}$ to $\left.3^{\prime}\right)$ : NCoA3 forward CTTTGGGCATTCCTGAACTTGTC, NCoA3 reverse GCCTCATCACCGCAGCAC, IRF8 forward GGAGTGCGGTCGCTCTGAAA, IRF8 reverse GTCGTAGGTGGTGTACCCCGTCA, Cyclophilin A forward AGTGGTTGGATGGCAAGC, Cyclophilin A reverse GATTCTAGGATACTGCGAGCAAA. PCR reactions were carried out with a denaturation step of $10 \mathrm{~min}$ at $95^{\circ} \mathrm{C}$ followed by forty-five cycles of $10 \mathrm{~s}$ at $95^{\circ} \mathrm{C}, 5 \mathrm{~s}$ at annealing temperature $\left(55^{\circ} \mathrm{C}\right.$ for $\mathrm{NCoA3}$ and Cyclophilin $\mathrm{A}$, $59^{\circ} \mathrm{C}$ for IRF8) and $20 \mathrm{~s}$ amplification at $72^{\circ} \mathrm{C}$. Quantifications of cDNAs were determined in reference to a standard curve prepared by amplification of serial dilutions of PCR product containing matching sequences. Analyses were performed using the second-derivative-maximum method provided by the Light Cycler quantification software, version 3.5 (Roche Diagnostics).

Quantification of gag viral mRNA was performed by realtime RT-PCR as described in [54].

\section{Nuclear extracts preparation}

For nuclear extract preparation, $10.10^{6}$ cells were harvested, washed and nuclei were isolated by addition of $150 \mu \mathrm{L}$ of buffer I ( $50 \mathrm{mM}$ Tris pH 7.9, $10 \mathrm{mM} \mathrm{KCl}, 10 \%$ glycerol, $1 \mathrm{mM}$ EDTA, $0.2 \% \mathrm{NP} 40$ ) followed by a centrifugation at $3000 \mathrm{~g}$ for $3 \mathrm{~min}$. Nuclear extracts were prepared by addition of $15 \mu \mathrm{L}$ of buffer II $(20 \mathrm{mM}$ Hepes $\mathrm{pH}$ $7.9,400 \mathrm{mM} \mathrm{NaCl}, 10 \mathrm{mM} \mathrm{KCl}, 20 \%$ glycerol, $1 \mathrm{mM}$ EDTA) for $20 \mathrm{~min}$ at $4{ }^{\circ} \mathrm{C}$ followed by a centrifugation at $15000 \mathrm{~g}$ for $10 \mathrm{~min}$. Protein concentrations were determined by the Bio-Rad protein assay.

\section{Western blot analysis}

Nuclear extracts $(100 \mu \mathrm{g})$ were loaded on $8 \%$ SDS-polyacrylamide gel and the proteins were transferred to nitrocellulose membrane (Hybond-C, Amersham) that was subsequently blocked for $1 \mathrm{~h}$ with $5 \%$ non-fat dry milk in PBS-T (PBS, 0.05\% Tween 20) and incubated with antibodies directed against NCoA3 (goat polyclonal antiACTR C-20, Santa Cruz Biotechnology, Inc.), IRF8 (goat polyclonal anti-ICSBP C-19, Santa Cruz Biotechnology, Inc.) or actin (mouse monoclonal anti-actin, Calbiochem) for $2 \mathrm{~h}$. The membranes were then washed and incubated with secondary antibodies conjugated to horseradish peroxidase (HRP conjugated rabbit anti-goat (DakoCytomation) or goat anti-mouse (Calbiochem) 
immunoglobulins). Hybridizations were revealed using an ECL enhanced chemiluminescence kit (ECL, Amersham). The quantification was done using the Image Tools (Syngene) software.

\section{Transient transfection and enzymatic assays}

HEK293 cells were transfected using calcium phosphate co-precipitation method. Cells were lysed $24 \mathrm{~h}$ after transfection with a buffer containing $60 \mathrm{mM} \mathrm{Na}_{2} \mathrm{HPO}_{4}, 40 \mathrm{mM}$ $\mathrm{NaH}_{2} \mathrm{PO}_{4}, 10 \mathrm{mM} \mathrm{KCl}, 10 \mathrm{mM} \mathrm{MgSO}_{4}, 2.5 \mathrm{mM}$ EDTA, 50 $\mathrm{mM} \beta$-mercaptoethanol and $0.125 \%$ Nonidet P-40. Luciferase activities were measured as previously described [55]. Cotransfection with pCMV-LacZ plasmid was performed to normalize transfection efficiency and $\beta$-galactosidase activities were determined using Chlorophenol red $\beta$-D-galactopyranoside (CPRG, Roche Diagnostics) assay as previously described [55]. The normalized luciferase index (NLI) was defined as the ratio of luciferase to $\beta$-galactosidase activities.

\section{Competing interests}

The author(s) declare that they have no competing interests.

\section{Authors' contributions}

SM performed the microarray analyses, real-time RT-PCR and drafted the manuscript. DD and LC carried out realtime RT-PCR, Western blot and transfection experiments. AG participated in transfection experiments. UH conceived the study, participated in its design and coordination and helped to draft and finalize the manuscript. All authors read and approved the final manuscript.

\section{Additional material}

\section{Additional File 1}

Genes upregulated in $\mathrm{U} 1$ and $\mathrm{ACH}-2$ cells.

Click here for file

[http://www.biomedcentral.com/content/supplementary/1742-

4690-2-73-S1.doc]

\section{Additional File 2}

Genes specifically upregulated in $\mathrm{U} 1$ cells.

Click here for file

[http://www.biomedcentral.com/content/supplementary/1742-

4690-2-73-S2.doc]

\section{Additional File 3}

Genes specifically upregulated in ACH-2 cells.

Click here for file

[http://www.biomedcentral.com/content/supplementary/1742-

4690-2-73-S3.doc]

\section{Additional File 4}

Genes downregulated in $\mathrm{U} 1$ and $\mathrm{ACH}-2$ cells.

Click here for file

[http://www.biomedcentral.com/content/supplementary/1742-

4690-2-73-S4.doc]

\section{Additional File 5}

Genes specifically downregulated in U1 cells.

Click here for file

[http://www.biomedcentral.com/content/supplementary/1742-

4690-2-73-S5.doc]

\section{Additional File 6}

Genes specifically downregulated in ACH-2 cells.

Click here for file

[http://www.biomedcentral.com/content/supplementary/1742-

4690-2-73-S6.doc]

\section{Acknowledgements}

We thank Drs. S. Emiliani, B.Z. Levi, P.S. Meltzer, T. Taniguchi, M. Alizon for providing plasmids, and the National Institutes of Health AIDS Research and Reference Reagent Program for the kind gift of reagents. We are grateful to Dr. C. Thibault for her precious help in microarray hybridization data mining. L.C. holds a fellowship from the Ministère de l'Education Nationale, de l'Enseignement Supérieur et de la Recherche. S.M. is supported by a grant from Sidaction. Sidaction (AOI5) supported this work. We thank S. Nisole for helpful discussion.

\section{References}

I. Pomerantz RJ, Horn DL: Twenty years of therapy for HIV-I infection. Nat Med 2003, 9:867-873.

2. Pierson T, McArthur J, Siliciano RF: Reservoirs for HIV-I: mechanisms for viral persistence in the presence of antiviral immune responses and antiretroviral therapy. Annu Rev Immunol 2000, I8:665-708.

3. Wong JK, Hezareh M, Gunthard HF, Havlir DV, Ignacio CC, Spina CA, Richman DD: Recovery of replication-competent HIV despite prolonged suppression of plasma viremia. Science 1997, 278: $129 \mid-1295$.

4. Finzi D, Hermankova M, Pierson T, Carruth LM, Buck C, Chaisson RE, Quinn TC, Chadwick K, Margolick J, Brookmeyer R, Gallant J, Markowitz M, Ho DD, Richman DD, Siliciano RF: Identification of a reservoir for HIV-I in patients on highly active antiretroviral therapy. Science 1997, 278:1295-1300.

5. Chun TW, Stuyver L, Mizell SB, Ehler LA, Mican JA, Baseler M, Lloyd AL, Nowak MA, Fauci AS: Presence of an inducible HIV-I latent reservoir during highly active antiretroviral therapy. Proc Natl Acad SciU S A 1997, 94: 13193-13197.

6. Blankson JN, Persaud D, Siliciano RF: The challenge of viral reservoirs in HIV-I infection. Annu Rev Med 2002, 53:557-593.

7. Lassen K, Han Y, Zhou Y, Siliciano J, Siliciano RF: The multifactorial nature of HIV-I latency. Trends Mol Med 2004, 10:525-53I.

8. Finzi D, Blankson J, Siliciano JD, Margolick JB, Chadwick K, Pierson T, Smith K, Lisziewicz J, Lori F, Flexner C, Quinn TC, Chaisson RE, Rosenberg E, Walker B, Gange S, Gallant J, Siliciano RF: Latent infection of CD4(+) T cells provides a mechanism for lifelong persistence of HIV-I, even in patients on effective combination therapy. Nat Med 1999, 5:512-517.

9. Williams SA, Greene WC: Host factors regulating post-integration latency of HIV. Trends Microbiol 2005, 13:137-139.

10. He G, Ylisastigui L, Margolis DM: The regulation of HIV-I gene expression: the emerging role of chromatin. DNA Cell Biol 2002, $21: 697-705$. 
11. Verdin E, Paras PJ, Van Lint C: Chromatin disruption in the promoter of human immunodeficiency virus type I during transcriptional activation. Embo J 1993, I 2:3249-3259.

12. Henderson A, Holloway A, Reeves R, Tremethick DJ: Recruitment of SWI/SNF to the human immunodeficiency virus type I promoter. Mol Cell Biol 2004, 24:389-397.

13. Lusic M, Marcello A, Cereseto A, Giacca M: Regulation of HIV-I gene expression by histone acetylation and factor recruitment at the LTR promoter. Embo J 2003, 22:6550-656I.

14. Kato-Maeda M, Gao Q, Small PM: Microarray analysis of pathogens and their interaction with hosts. Cell Microbiol 200I 3:713-719.

15. Shaheduzzaman S, Krishnan V, Petrovic A, Bittner M, Meltzer P, Trent J, Venkatesan S, Zeichner S: Effects of HIV-I Nef on cellular gene expression profiles. J Biomed Sci 2002, 9:82-96.

16. Simmons A, Aluvihare $V$, McMichael A: Nef triggers a transcriptional program in $T$ cells imitating single-signal $T$ cell activation and inducing HIV virulence mediators. Immunity $200 \mathrm{I}$ 14:763-777.

17. De la Fuente C, Santiago F, Deng L, Eadie C, Zilberman I, Kehn K Maddukuri A, Baylor S, Wu K, Lee CG, Pumfery A, Kashanchi F: Gene expression profile of HIV-I Tat expressing cells: a close interplay between proliferative and differentiation signals. BMC Biochem 2002, 3:14.

18. Izmailova E, Bertley FM, Huang Q, Makori N, Miller CJ, Young RA, Aldovini A: HIV-I Tat reprograms immature dendritic cells to express chemoattractants for activated $\mathrm{T}$ cells and macrophages. Nat Med 2003, 9:191-197.

19. Cicala C, Arthos J, Selig SM, Dennis GJ, Hosack DA, Van Ryk D, Spangler ML, Steenbeke TD, Khazanie P, Gupta N, Yang J, Daucher M, Lempicki RA, Fauci AS: HIV envelope induces a cascade of cell signals in non-proliferating target cells that favor virus replication. Proc Natl Acad Sci U S A 2002, 99:9380-9385.

20. Janket ML, Manickam P, Majumder B, Thotala D, Wagner M, Schafer EA, Collman RG, Srinivasan A, Ayyavoo V: Differential regulation of host cellular genes by HIV-I viral protein $R(\mathrm{Vpr})$ : cDNA microarray analysis using isogenic virus. Biochem Biophys Res Commun 2004, 314: I I26-1 I32.

21. Corbeil J, Sheeter D, Genini D, Rought S, Leoni L, Du P, Ferguson M, Masys DR, Welsh JB, Fink JL, Sasik R, Huang D, Drenkow J, Richman $\mathrm{DD}$, Gingeras T: Temporal gene regulation during HIV-I infection of human CD4+ T cells. Genome Res 200 I, II:I198-1204.

22. Geiss GK, Bumgarner RE, An MC, Agy MB, van 't Wout AB, Hammersmark E, Carter VS, Upchurch D, Mullins JI, Katze MG: Largescale monitoring of host cell gene expression during HIV-I infection using CDNA microarrays. Virology 2000, 266:8-16.

23. Van 't Wout AB, Lehrman GK, Mikheeva SA, O'Keeffe GC, Katze MG, Bumgarner RE, Geiss GK, Mullins Jl: Cellular gene expression upon human immunodeficiency virus type I infection of CD4(+)-T-cell lines. J Virol 2003, 77: $1392-1402$

24. Wen W, Chen S, Cao Y, Zhu Y, Yamamoto Y: HIV-I infection initiates changes in the expression of a wide array of genes in U937 promonocytes and HUT78 T cells. Virus Res 2005.

25. Vahey MT, Nau ME, Jagodzinski LL, Yalley-Ogunro J, Taubman M, Michael NL, Lewis MG: Impact of viral infection on the gene expression profiles of proliferating normal human peripheral blood mononuclear cells infected with HIV type I RF. AIDS Res Hum Retroviruses 2002, 18:179-192.

26. Chun TW, Justement JS, Lempicki RA, Yang J, Dennis GJ, Hallahan CW, Sanford C, Pandya P, Liu S, McLaughlin M, Ehler LA, Moir S, Fauci AS: Gene expression and viral prodution in latently infected, resting CD4+ $\mathrm{T}$ cells in viremic versus aviremic HIV-infected individuals. Proc Natl Acad Sci U S A 2003, 100:1908-1913.

27. Krishnan V, Zeichner SL: Host cell gene expression during human immunodeficiency virus type I latency and reactivation and effects of targeting genes that are differentially expressed in viral latency. I Virol 2004, 78:9458-9473.

28. Xu J, Li Q: Review of the in vivo Functions of the p 160 Steroid Receptor Coactivator Family. Mol Endocrinol 2003, I 2: I 2

29. Levi BZ, Hashmueli S, Gleit-Kielmanowicz M, Azriel A, Meraro D ICSBP/IRF-8 transactivation: a tale of protein-protein interaction. J Interferon Cytokine Res 2002, 22:153-160.

30. Bosinger SE, Hosiawa KA, Cameron MJ, Persad D, Ran L, Xu L, Boulassel MR, Parenteau M, Fournier J, Rud EW, Kelvin DJ: Gene expression profiling of host response in models of acute HIV infection. J Immunol 2004, 1 73:6858-6863.
31. Kino T, Slobodskaya O, Pavlakis GN, Chrousos GP: Nuclear receptor coactivator p 160 proteins enhance the HIV-I long terminal repeat promoter by bridging promoter-bound factors and the Tat-P-TEFb complex. B Biol Chem 2002, 277:2396-2405.

32. Sgarbanti M, Borsetti A, Moscufo N, Bellocchi MC, Ridolfi B, Nappi F, Marsili G, Marziali G, Coccia EM, Ensoli B, Battistini A: Modulation of human immunodeficiency virus I replication by interferon regulatory factors. J Exp Med 2002, 195: I359-1370.

33. Van Lint C, Amella CA, Emiliani S, John M, Jie T, Verdin E: Transcription factor binding sites downstream of the human immunodeficiency virus type I transcription start site are important for virus infectivity. J Virol 1997, 71:61| 3-6127.

34. Thornton AM, Ogryzko VV, Dent A, Sharf R, Levi BZ, Kanno Y, Staudt LM, Howard BH, Ozato K: A dominant negative mutant of an IFN regulatory factor family protein inhibits both type I and type II IFN-stimulated gene expression and antiproliferative activity of IFNs. J Immunol I996, I 57:5 I 45-5I 54

35. Herrmann CH, Carroll RG, Wei P, Jones KA, Rice AP: Tat-associated kinase, TAK, activity is regulated by distinct mechanisms in peripheral blood lymphocytes and promonocytic cell lines. J Virol 1998, 72:988I-9888.

36. Van 't Wout AB, Swain JV, Schindler M, Rao U, Pathmajeyan MS, Mullins Jl, Kirchhoff F: Nef induces multiple genes involved in cholesterol synthesis and uptake in human immunodeficiency virus type I-infected T cells. J Virol 2005, 79: | 0053-10058.

37. Krishnan V, Zeichner SL: Alterations in the expression of DEAD-box and other RNA binding proteins during HIV-I replication. Retrovirology 2004, I:42.

38. Marks P, Rifkind RA, Richon VM, Breslow R, Miller T, Kelly WK: Histone deacetylases and cancer: causes and therapies. Nat Rev Cancer 2001, I: 194-202.

39. Brigati C, Giacca M, Noonan DM, Albini A: HIV Tat, its TARgets and the control of viral gene expression. FEMS Microbiol Lett 2003, 220:57-65.

40. Chen H, Lin RJ, Schiltz RL, Chakravarti D, Nash A, Nagy L, Privalsky ML, Nakatani Y, Evans RM: Nuclear receptor coactivator ACTR is a novel histone acetyltransferase and forms a multimeric activation complex with P/CAF and CBP/p300. Cell 1997, 90:569-580.

4I. El Kharroubi A, Martin MA: cis-acting sequences located downstream of the human immunodeficiency virus type I promoter affect its chromatin structure and transcriptional activity. Mol Cell Biol 1996, 16:2958-2966.

42. Battistini A, Marsili G, Sgarbanti M, Ensoli B, Hiscott J: IRF regulation of HIV-I long terminal repeat activity. J Interferon Cytokine Res 2002, 22:27-37.

43. Marsili G, Borsetti A, Sgarbanti M, Remoli AL, Ridolfi B, Stellacci E, Ensoli $B$, Battistini $A$ : On the role of interferon regulatory factors in HIV-I replication. Ann N Y Acad Sci 2003, I01 0:29-42.

44. Sgarbanti M, Marsili G, Remoli AL, Ridolfi B, Stellacci E, Borsetti A, Ensoli $B$, Battistini A: Analysis of the signal transduction pathway leading to human immunodeficiency virus-I-induced interferon regulatory factor-I upregulation. Ann N Y Acad Sci 2004, 1030: 187-195.

45. Emiliani S, Van Lint C, Fischle W, Paras PJ, Ott M, Brady J, Verdin E: A point mutation in the HIV-I Tat responsive element is associated with postintegration latency. Proc Natl Acad Sci U S A 1996, 93:6377-638I.

46. Emiliani S, Fischle W, Ott M, Van Lint C, Amella CA, Verdin E: Mutations in the tat gene are responsible for human immunodeficiency virus type I postintegration latency in the $\mathrm{UI}$ cell line. Jirol 1998, 72:1666-1670.

47. Clouse KA, Powell D, Washington I, Poli G, Strebel K, Farrar W, Barstad P, Kovacs J, Fauci AS, Folks TM: Monokine regulation of human immunodeficiency virus-I expression in a chronically infected human T cell clone. J Immunol 1989, I 42:43I-438.

48. Perez VL, Rowe T, Justement JS, Butera ST, June $\mathrm{CH}$, Folks TM: An HIV-I-infected $T$ cell clone defective in IL-2 production and $\mathrm{Ca2}+$ mobilization after CD3 stimulation. I Immunol |99|, |47:3|45-3|48.

49. Folks TM, Justement J, Kinter A, Schnittman S, Orenstein J, Poli G, Fauci AS: Characterization of a promonocyte clone chronically infected with HIV and inducible by I3-phorbol- I-myristate acetate. J Immunol 1988, I 40:1 II 7-I I 22.

50. Butera ST, Perez VL, Wu BY, Nabel G], Folks TM: Oscillation of the human immunodeficiency virus surface receptor is regu- 
lated by the state of viral activation in a CD4+ cell model of chronic infection. J Virol 199I, 65:4645-4653.

5I. Hazan U, Thomas D, Alcami J, Bachelerie F, Israël N, Yssel H, Virelizier JL, Arenzana-Seisdedos F: Stimulation of human T-cell clone with anti-CD3 or tumor necrosis factor induces NF-kappa B translocation but not human immunodeficiency virus I enhancer-dependent transcription. Proc Natl Acad Sci USA 1990, 87:786I-7865.

52. Anzick SL, Kononen J, Walker RL, Azorsa DO, Tanner MM, Guan XY, Sauter G, Kallioniemi OP, Trent JM, Meltzer PS: AIB I, a steroid receptor coactivator amplified in breast and ovarian cancer. Science 1997, 277:965-968.

53. El Kharroubi A, Verdin E: Protein-DNA interactions within DNase I-hypersensitive sites located downstream of the HIV-I promoter. J Biol Chem 1994, 269:19916-19924.

54. Brussel A, Sonigo P: Evidence for gene expression by unintegrated human immunodeficiency virus type I DNA species. J Virol 2004, 78: I | 263-I I 27|.

55. Dumonceaux J, Nisole S, Chanel C, Quivet L, Amara A, Baleux F, Briand $P$, Hazan U: Spontaneous mutations in the env gene of the human immunodeficiency virus type I NDK isolate are associated with a CD4-independent entry phenotype. J Virol 1998, 72:512-519.

Publish with Bio Med Central and every scientist can read your work free of charge

"BioMed Central will be the most significant development for disseminating the results of biomedical research in our lifetime. "

Sir Paul Nurse, Cancer Research UK

Your research papers will be:

- available free of charge to the entire biomedical community

- peer reviewed and published immediately upon acceptance

- cited in PubMed and archived on PubMed Central

- yours - you keep the copyright

Submit your manuscript here:

http://www.biomedcentral.com/info/publishing_adv.asp
BiolMedcentral 